\title{
Investigation of Likelihood of Cracking in Reinforced Concrete Bridge Decks
}

\author{
Adel ElSafty ${ }^{1)}$, and Ahmed Abdel-Mohti ${ }^{2), *}$
}

(Received December 30, 2012, Accepted January 15, 2013)

\begin{abstract}
One of the biggest problems affecting bridges is the transverse cracking and deterioration of concrete bridge decks. The causes of early age cracking are primarily attributed to plastic shrinkage, temperature effects, autogenous shrinkage, and drying shrinkage. The cracks can be influenced by material characteristics, casting sequence, formwork, climate conditions, geometry, and time dependent factors. The cracking of bridge decks not only creates unsightly aesthetic condition but also greatly reduces durability. It leads to a loss of functionality, loss of stiffness, and ultimately loss of structural safety. This investigation consists of field, laboratory, and analytical phases. The experimental and field testing investigate the early age transverse cracking of bridge decks and evaluate the use of sealant materials. The research identifies suitable materials, for crack sealing, with an ability to span cracks of various widths and to achieve performance criteria such as penetration depth, bond strength, and elongation. This paper also analytically examines the effect of a wide range of parameters on the development of cracking such as the number of spans, the span length, girder spacing, deck thickness, concrete compressive strength, dead load, hydration, temperature, shrinkage, and creep. The importance of each parameter is identified and then evaluated. Also, the AASHTO Standard Specification limits liveload deflections to $L / 800$ for ordinary bridges and $L / 1000$ for bridges in urban areas that are subject to pedestrian use. The deflection is found to be an important parameter to affect cracking. A set of recommendations to limit the transverse deck cracks in bridge decks is also presented.
\end{abstract}

Keywords: deck, overlay, bridge, cracking, deterioration, shrinkage, creep.

\section{Introduction}

Although cracking can occur in hardened mature concrete, transverse deck cracking are more likely to occur in bridge decks in early ages. The cracking has been observed in reinforced concrete bridge decks in the State of Florida and in other bridges around the nation. Numerous factors can lead to transverse deck cracking in highway bridges including time dependent material properties, restraints, casting sequence, formwork, and environmental factors. Several studies investigated the issue of deck cracking (ACI 2001; Altoubat and Lange 2000; Cady et al. 1971; Eppers et al. 1998; Frosch et al. 2003; Krauss and Rogalla 1996; PCA 1970; Purvis et al. 1995; Saadeghvaziri and Hadidi 2002; Schmitt and Darwin 1995; Xi et al. 2003). Also, the development of cracking increases the effect of freeze and

\footnotetext{
${ }^{1)}$ Department of Civil Engineering,

School of Engineering, University of North Florida, Jacksonville, FL 32224, USA.

${ }^{2)}$ Civil Engineering Department, Ohio Northern

University, Ada, OH 45810, USA.

*Corresponding Author; E-mail: a-abdel-mohti@onu.edu Copyright ( $\odot$ The Author(s) 2013. This article is published with open access at Springerlink.com
}

thaw cycles, which may lead to spalling of concrete and thus resulting in corrosion of steel reinforcement. Transverse deck cracking also increases carbonation and chloride penetration leading to accelerated corrosion. Also, a possible damage to underlying components may take place and the bridge may experience premature deterioration; therefore the bridge may experience loss of stiffness and eventually a loss of function. Transverse cracks can reduce the service life of structures and increase maintenance costs. Moreover, cracking will lead to undesirable aesthetic condition of the bridge. The developed cracks are full-depth cracks and are typically spaced at $92-305 \mathrm{~cm}$ apart. They are the most frequently observed cracks in concrete bridge decks.

There are several mechanisms contributing to cracking of hardened concrete of which three are important, namely, drying shrinkage, autogenous shrinkage, and thermal stresses. Restrained drying shrinkage occurs due to the volume change induced by a loss of moisture in the cement paste. The concrete would not crack if this shrinkage could occur without the restraint from structural elements, the subgrade, or the moist interior of the concrete itself. This volume change coupled with restraint cause tensile stresses in the concrete that can lead to cracking. These tensile stresses are influenced by the amount and rate of shrinkage, the degree of restraint, the modulus of elasticity, and the amount of creep. The amount of drying shrinkage is a function of the amount and type of aggregate and the cement paste content 
of the concrete. Methods to reduce shrinkage cracking include using contraction joints, careful detailing of reinforcement, shrinkage-compensating admixtures, and reducing the sub slab restraint. Autogenous shrinkage is a special type of drying shrinkage resulting from self-desiccation or internal drying that occurs in concrete with water-cementitious (w/c) materials below 0.42 . This type of shrinkage differs from typical drying shrinkage since there is no loss of moisture from the bulk concrete. Autogenous shrinkage strain is typically about $40-100$ microstrain, but has been measured as high as 2,300 microstrain in concrete with a $\mathrm{w} / \mathrm{cm}$ ratio of 0.2 . Autogenous shrinkage has been found to increase with increasing temperature, cement content, and cement fineness. Temperature differences in a concrete structure result in volume changes causing tensile stresses. The dissipation of the heat of hydration of cement and changes in ambient temperature can create temperature differentials that cause tensile stresses in concrete structures. These tensile stresses are proportional to the temperature differential, the coefficient of thermal expansion, the effective modulus of elasticity, and the degree of restraint. Methods of reducing thermal cracking include reducing maximum internal core temperature, delaying the onset of surface cooling, controlling the rate at which the concrete cools, and increasing the early age tensile strength of the concrete (PCA 1970).

The earliest noted study was conducted by the Portland Cement Association, the Bureau of Public Roads, and ten state highway departments. This study was released in 1970. The purpose of the study (PCA 1970) was to determine concrete bridge deck durability problems, causes of the types of deterioration, methods to improve durability, and methods to inhibit existing deterioration. In this study, transverse cracking was observed as the most common type of cracking. Older decks and longer spans showed more transverse cracking, whereas continuous span bridges and those with steel girders appeared to exacerbate transverse cracking.

In a study conducted for the Pennsylvania Department of Transportation, researchers surveyed 4 year old bridge decks in Pennsylvania to investigate the extent and causes of concrete bridge deck deterioration (Cady et al. 1971). The researchers found transverse cracks in $60 \%$ of all spans and $71 \%$ of all bridges. Also, bridges in Pennsylvania were assessed through 99 field surveys and 12 thorough surveys to determine the causes of transverse cracking. These surveys included crack mapping, crack width measurements, rebar location and depth surveys, concrete coring, and construction records. An important finding made by the researchers was that the transverse cracks intersected coarse aggregate particles; this indicates that transverse cracking occurs in hardened concrete rather than plastic concrete.

Schmitt and Darwin (1995) conducted a study on the effects of different variables on bridge deck cracking, classifying the variables into five categories: material properties, site conditions, construction procedures, design specifications, and traffic and age. The material properties considered included admixtures, slump, percent volume of water and cement, water content, cement content, water-cement ratio, air content, and compressive strength. Site condition factors considered in the study were average air temperature, low air temperature, high air temperature, daily temperature range, relative humidity, average wind velocity, and evaporation. The construction procedure factors considered, in the study, were placing sequence, length of placement, and curing. There were no observed relationships between length of placement or type of curing materials and cracking. There were not any correlation determined between cracking and placing sequence due to the lack of information. Design factors considered in the study included structure type, deck type, deck thickness, top cover, transverse reinforcing bar size, transverse reinforcing bar spacing, girder end conditions, span length, bridge length, span type, and skew. Regarding traffic and age, the researchers found that cracking increased with traffic volume and that bridges constructed, prior to 1988 , exhibited less cracking than bridges constructed after 1988. The increase in cracking, in newer bridges, was attributed to changes in construction, material properties, and design specifications.

Krauss and Rogalla (1996) conducted, what is likely, the most comprehensive study to date. They surveyed 52 transportation agencies in the United States and Canada to evaluate early age transverse cracking. Over 100,000 bridges were found to have developed early transverse cracks. Analytical studies were also performed using both theoretical and finite element analysis to evaluate the influence of several parameters on transverse cracking. The researchers determined that span type, concrete strength, and girder type were the most important design factors influencing transverse cracking. Material properties such as cement content, cement composition, early-age elastic modulus, creep, aggregate type, heat of hydration, and drying shrinkage also influenced deck cracking. Researchers conducted a field investigation of 72 bridge decks in Minnesota. The researchers determined that the most related design factors to transverse cracking were longitudinal restraint, deck thickness, and top transverse bar size. The material factors that affect transverse cracking the most were cement content, aggregate type and quantity, and air content. Researchers in Minnesota performed a parametric study considering bridges with steel and prestressed concrete girders. Among variables considered for steel girder bridges were end conditions, girder stiffness, locations of cross frames, girder splices, supplemental reinforcing bars, shrinkage properties, concrete modulus of elasticity, and temperature differential due to heat of hydration. Variables considered for prestressed girder bridges were the times casting in relation to the times of both strand release and deck casting and shrinkage properties of the deck and girders.

From a research sponsored by the Indiana Department of Transportation, researchers conducted a field study and constructed laboratory specimens to investigate the behavior of transverse cracks (Frosch et al. 2003). Using these specimens, the researchers evaluated the effect of differing bridge deck designs on the control of overall shrinkage and evaluated the contribution of stay-in-place (SIP) steel forms to the formation of transverse cracking. 


\subsection{Crack Sealers}

The most commonly marketed sealers include; epoxies, reactive methyl methacrylates (MMA), methacrylates, highmolecular weight methacrylates (HMWM), and polyurethanes. All of these products have distinct characteristics that make them favorable for some uses and unfavorable for others. Properties of sealers include volatility, viscosity, initial shrinkage, tensile strength, and tensile elongation. From surveys of 40 states, $60 \%$ indicated that they did not have a crack sealing program and $24 \%$ use epoxies and methacrylates, however, none were asked about HMWMs, MMAs, or polyurethane resins (Soriano 2002; Tsiatas and Robinson 2002). Another survey stated that epoxy was the predominant sealer (Tsiatas and Robinson 2002). Only four of sixteen states that had a crack sealing program, claimed to use HMWM sealers.

This research concentrates on epoxies and methacrylates, both HMWM and MMA, as they possess the properties closest to the requirements in the qualified products list (QPL) of the Florida Department of Transportation. Also, an analytical investigation is conducted to identify major parameters affecting the likelihood of cracking and to provide recommendation to limit cracking of bridge decks.

\section{Experimental Investigation}

The experimental phase of this study consisted of field and laboratory investigations to identify the most appropriate sealant materials suitable for crack sealing. Four milestone sealant materials are considered, MMA, HMWM, Polyurethane, and epoxy. The performance of the sealers is evaluated based on meeting a number of performance criteria. NCHRP indicated that crack sealers are measured in four primary ways including depth of penetration, bond strength, chloride content/resistance to corrosion, and seepage rate. It was decided to consider the elongation as well in this study when the performance is evaluated.

\subsection{Depth of Penetration}

The test for the depth of penetration for crack sealers is completely different from that of a concrete sealant. Sealers are used to cover or fill an already formed crack. It is presumed that the larger the depth a sealer can penetrate, the better the seal that it will create. Due to the variability of crack widths, it may be more useful to measure the percentage of penetration versus the actual penetration depth (Sprinkel 1998; Rodler et al. 1989; Eppers et al. 1998).

\subsection{Bond Strength}

The ability of a resin to repair the structural problem in a cracked deck is measured by its bond strength. Because there is no standard method to test for bond strength, engineers use a few different tests to determine bond strength. The most common test is the tensile splitting test-ASTM C496. Another method is the three-point bending flexural testASTM C293.

\subsection{Chloride Ingress and Corrosion}

Chloride ions can infiltrate the concrete and corrode the reinforcement if there exists any cracking on the bridge deck. Crack sealers act as a barrier to slow down this ingress of chloride ions into the concrete. This problem occurs mainly in the northern states where there is tendency of having freeze-thaw cycles and where the use of road salt for deicing is common.

\subsection{Seepage}

The indication of how well the repaired specimen prevents chloride ion ingress, is called seepage. Seepage is measured by the volume of water that passes through the cracked concrete. It is suggested that the least amount of water that passes through the crack, the better the rebar of the deck is protected. Several tests are used to check for seepage. One test involves forming a barrier around the top of the concrete core sample, after the sides are waterproofed; water is poured into the barrier on top of the core sample. The water height is kept constant while the rate in which water passes through the core is recorded. The number of leaks before the cracks were sealed is compared to the number of leaks, after the cracks are sealed. This test is mainly used in the field to give an indication of the success of the repair.

\subsection{Elongation}

There is a big variation for elongation of different sealers ranging between 3 and $60 \%$.

\section{Field Investigation}

In this phase of the study, a number of bridges were investigated in the field. The investigated bridges are all located in Florida including three bridges in Fort Lauderdale, eight bridges in Jacksonville, and the Pensacola bridge. An assessment to examine the issue of transverse deck cracking through determining the crack patterns and crack mapping was done for all of the bridges. For one of the bridges in Fort Lauderdale (Fig. 1), a total of 19 cracks were found on the

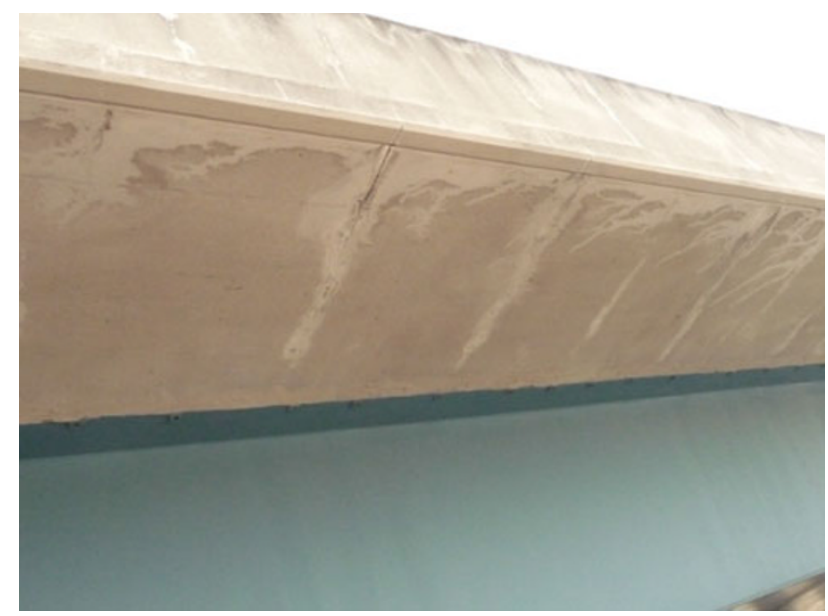

Fig. 1 Pictures of deck cracking in Fort Lauderdale, FL. 

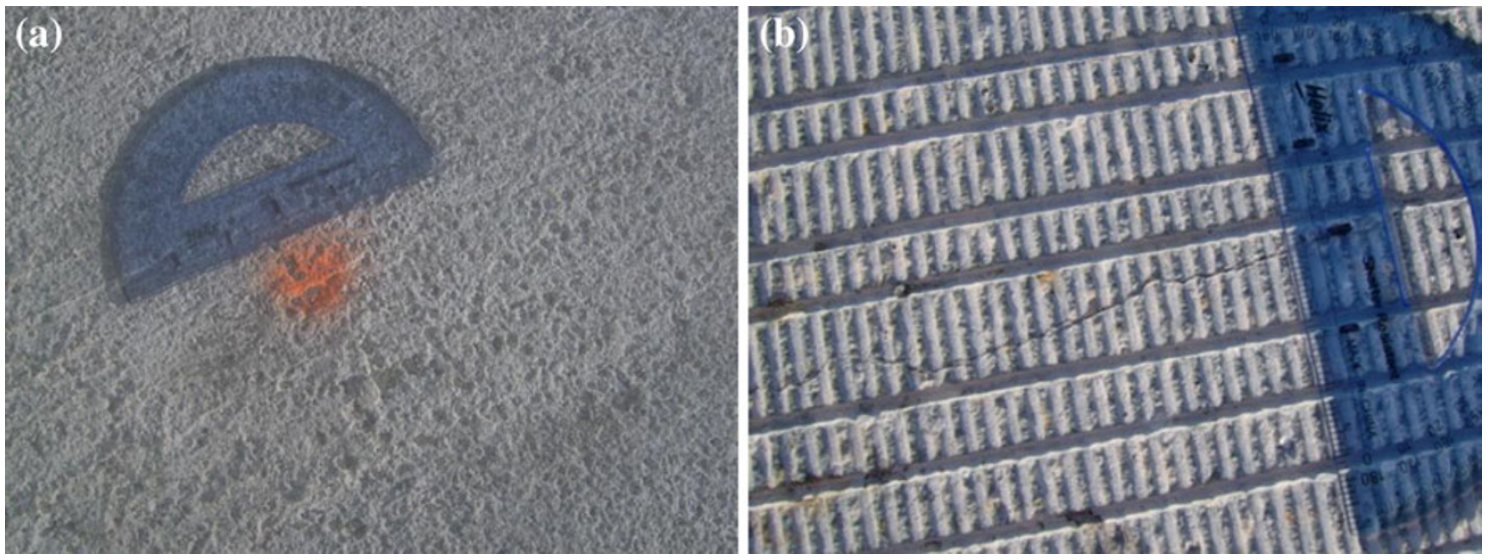

Fig. 2 Cracks in newly constructed bridge a before deck grooves b after deck grooves.

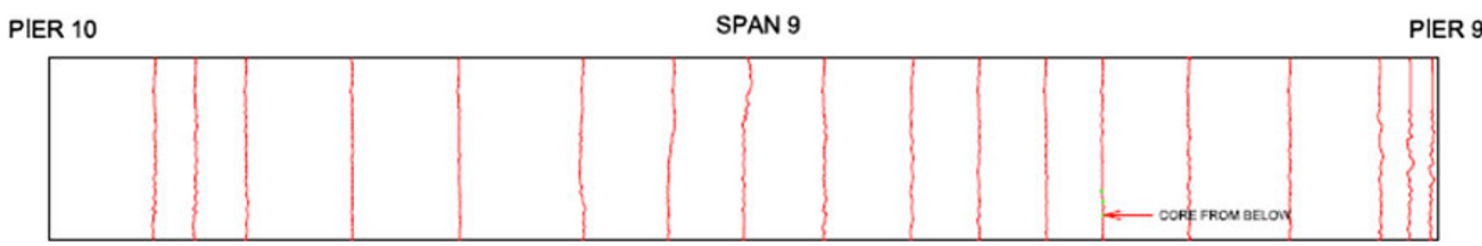

Fig. 3 Crack map of the Pensacola bridge.
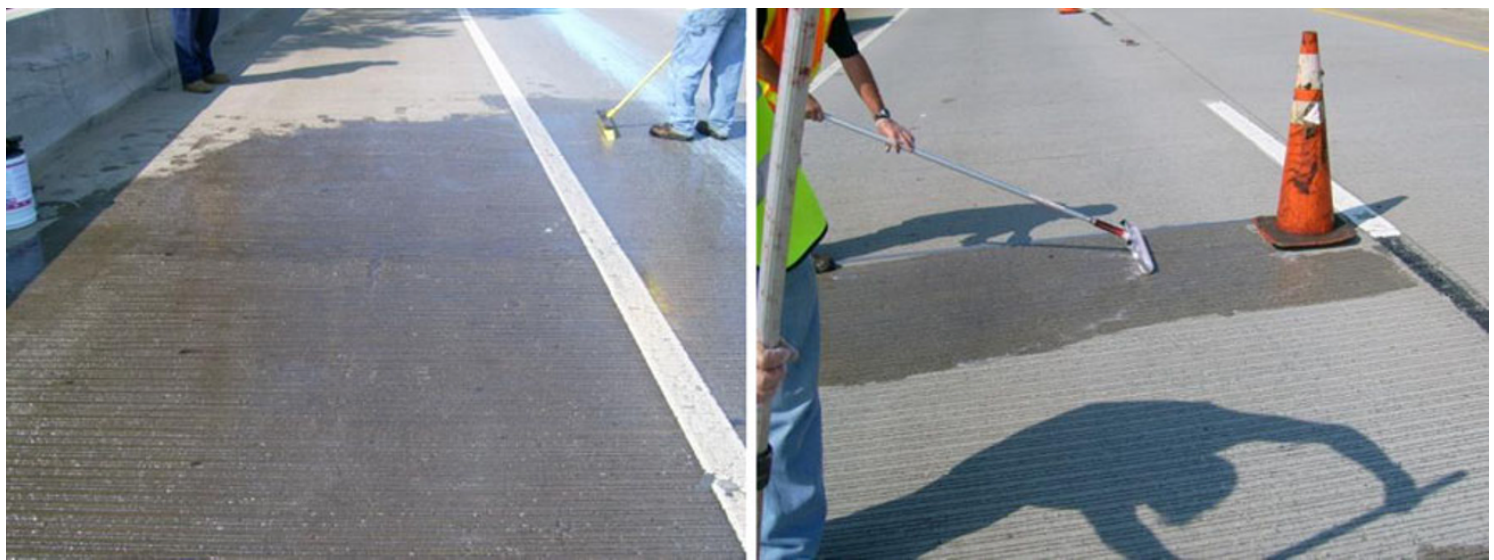

Fig. 4 Application of sealers to bridge areas.

top-side of the deck as well as 44 were found on the exterior bottom side of the deck. The average crack width for the cracks, documented on this bridge, ranged between 0.254 and $0.5 \mathrm{~mm}$. The lengths of the aforementioned transverse cracks ranged, approximately, from 0.92 to $11 \mathrm{~m}$ and became smaller in sections close to the parapet walls. The other two bridges in Fort Lauderdale have similar crack information to the one presented.

For a bridge in Jacksonville, A total of 134 cracks were found visible on the top side of the deck across the length of the section. The average crack widths were in the range between 0.076 and $0.635 \mathrm{~mm}$. The aforementioned cracks were recorded to have lengths between 0.12 and $10 \mathrm{~m}$. For another bridge in Jacksonville, only 35 cracks with an average crack width ranging from 0.025 to $0.432 \mathrm{~mm}$ were found. The lengths of these cracks were determined to range from 0.92 to $10 \mathrm{~m}$. For another bridge in Jacksonville, a total of 261 cracks across the length of the sections were found.
The depicted cracks have an average width ranging from 0.025 to $0.381 \mathrm{~mm}$ Most of the cracking occurs around midspan between piers and not over the piers. The lengths of these cracks ranged between 0.24 and $10 \mathrm{~m}$. For another bridge in Jacksonville, a total of 44 cracks were found throughout the length of the bridge section. Cracks were found to have crack width between 0.025 and $0.152 \mathrm{~mm}$. The cracks throughout this bridge are far less severe than the others recorded. Similarly, the lengths of the cracks only ranged between 0.49 and $10 \mathrm{~m}$. For another bridge in Jacksonville, a total of only 29 visible cracks were found and documented. It was found that the cracks present on the top side of the deck on the bridge have widths ranging from 0.025 to $0.127 \mathrm{~mm}$. The lengths of the cracks ranged from 0.43 to $9.8 \mathrm{~m}$. For another bridge in Jacksonville, a total of only 153 visual cracks were found. The ranges of the average widths of these cracks were from 0.025 to $0.203 \mathrm{~mm}$ with lengths recorded between 0.34 and $14 \mathrm{~m}$. In 
Table 1 Sealant test results.

\begin{tabular}{|c|c|c|c|c|c|c|c|}
\hline Test site \# & Product & Components & Viscosity (cps) & Elongation (\%) & Curing time $(\mathrm{h})$ & Skid ave. & $\begin{array}{c}\text { Tensile strength } \\
\text { ave. }(\mathrm{kN})\end{array}$ \\
\hline TS-1 & 1 & 2 part epoxy & 30 & 5.5 & $2-3$ & 62 & 7.08 \\
\hline TS-2 & 2 & $\begin{array}{l}3 \text { part } \\
\text { methacrylate }\end{array}$ & $5-20$ & $40-50$ & $4-6$ & 37 & 10.51 \\
\hline TS-3 & 3 & $\begin{array}{c}2 \text { comp } \\
\text { methacrylate }\end{array}$ & $5-15$ & 5.5 & 1 & 22 & 5.68 \\
\hline $\mathrm{NA}^{\mathrm{a}}$ & 4 & $\begin{array}{c}2 \text { comp } \\
\text { methacrylate }\end{array}$ & $1,100-1,500$ & $220-300$ & & - & - \\
\hline TS-5 & 5 & $\begin{array}{c}3 \text { part } \\
\text { methacrylate }\end{array}$ & $14-15$ & 20 & $4-6$ & 37 & 7.70 \\
\hline $\mathrm{NA}^{\mathrm{a}}$ & 6 & $\begin{array}{c}3 \text { part } \\
\text { methacrylate }\end{array}$ & $14-15$ & 30 & 6 & - & - \\
\hline TS-6 & 7 & Epoxy & 80 & 60 & 2 & $50 / 74$ & $9.95 / 9.96$ \\
\hline TS-4 & Control & No sealer applied & & & & 48 & 10.19 \\
\hline
\end{tabular}

${ }^{a}$ Not applied.
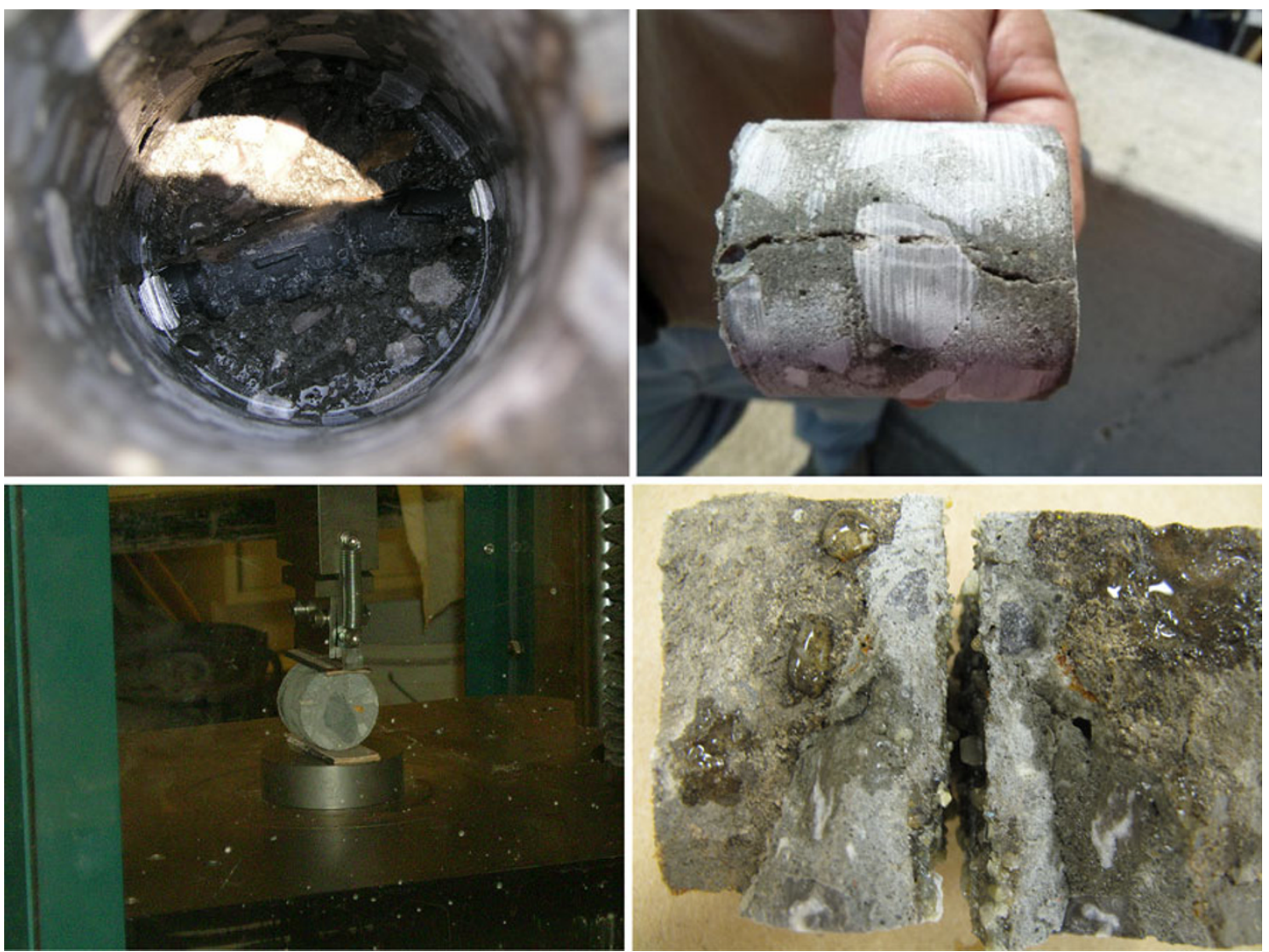

Fig. 5 Core removal, sampling, testing, and penetration.

general, the majority of the cracking, visible on the top side of the deck, was found around the mid-span of the sections between piers. In a newly constructed bridge in Jacksonville, the procedures for concrete placement and curing were followed as advised by many researchers; finishing of the concrete within 20 min of placement and a wet curing time for 10 days were done. Nonetheless, with following the proper procedures, the bridge deck began to show signs of transverse cracking within 30 days of concrete placement as 14 cracks developed on the day number 26 . The last bridge is a prestressed girder bridge with 14 spans. The bridge showed no signs of transverse cracking throughout its construction, however; during the placement of the last span, the concrete provider was replaced and consequently the new placed concrete began to crack after 36 days of concrete placement (Fig. 2). The compression test of the placed 
Table 2 Field test results.

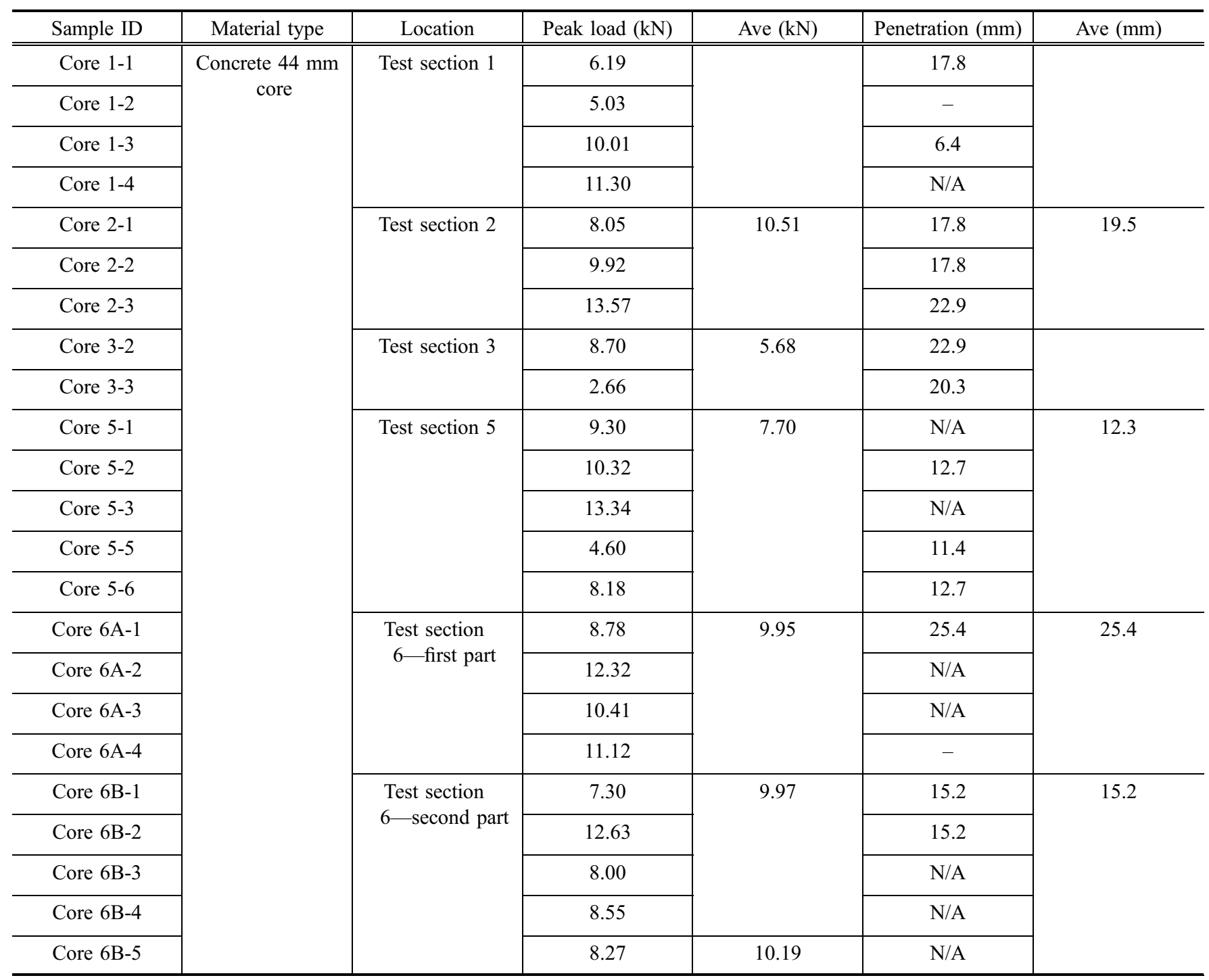

concrete showed that the concrete has a large compressive strength of 51.6 MPa, which verifies the conclusion of many researchers that bridge decks with high compression concrete have a higher tendency to develop transverse cracking.

Crack pattern in the bridges inspected, in Fort Lauderdale, is consistent with that in the Jacksonville's inspected bridges. Many transverse cracks have developed at mid span while a few have developed near the piers (negative moment region). There are evidences of some steel corrosion due to water leakage inside the steel box of one of the bridges in Fort Lauderdale. The location of corrosion is associated with the deck cracks identified at the top of the deck surface.

The Pensacola bridge is a 16 span steel girder bridge that developed severe transverse deck cracking (Fig. 3). Most of the cracks, in the bridge, developed around the transverse rebars and propagated all the way across to the parapet wall. This bridge was used for the field testing of the sealers in order to identify the appropriate sealant materials among those tested. The manufacturers of the sealant materials were contacted to provide the materials and a crew to mix and apply the products to avoid any nulled results. The field test was conducted. The east-bound right hand lane and shoulder of the bridge was divided into six sections; each section was about 6 by $6 \mathrm{~m}$. The sealers were applied to the designated areas (Fig. 4). Sealants are field tested on bridges for performance by chloride sampling cores, drill dust samples, water flooding of the treated deck areas to check water leak, core tests to determine the depth of sealant penetration, use dissection/stereo microscopes to determine resin depth and fluorescent, and long-wave UV lighting. After the surface was prepared and the cracks were cleaned properly, the sealant materials were applied according to the specified procedure in the manufacturer's data sheet and consequently the sand was sprinkled to provide skid resistance. Table 1 shows the field test results for the five sealants applied to the parts of the same bridge. The deck surface was allowed to dry for the required time of each product. Core samples were taken, after curing of the sealant, at random locations in each test area while tests were performed in accordance to ASTM C-496. The cores and testing procedure are shown in Fig. 5 and results are shown in Table 2. It was found that the average penetration of the sealant materials, in the cracks, ranged from 12.7 to $25.4 \mathrm{~mm}$. However, it should be noted that crack width was found to vary. All of the employed 

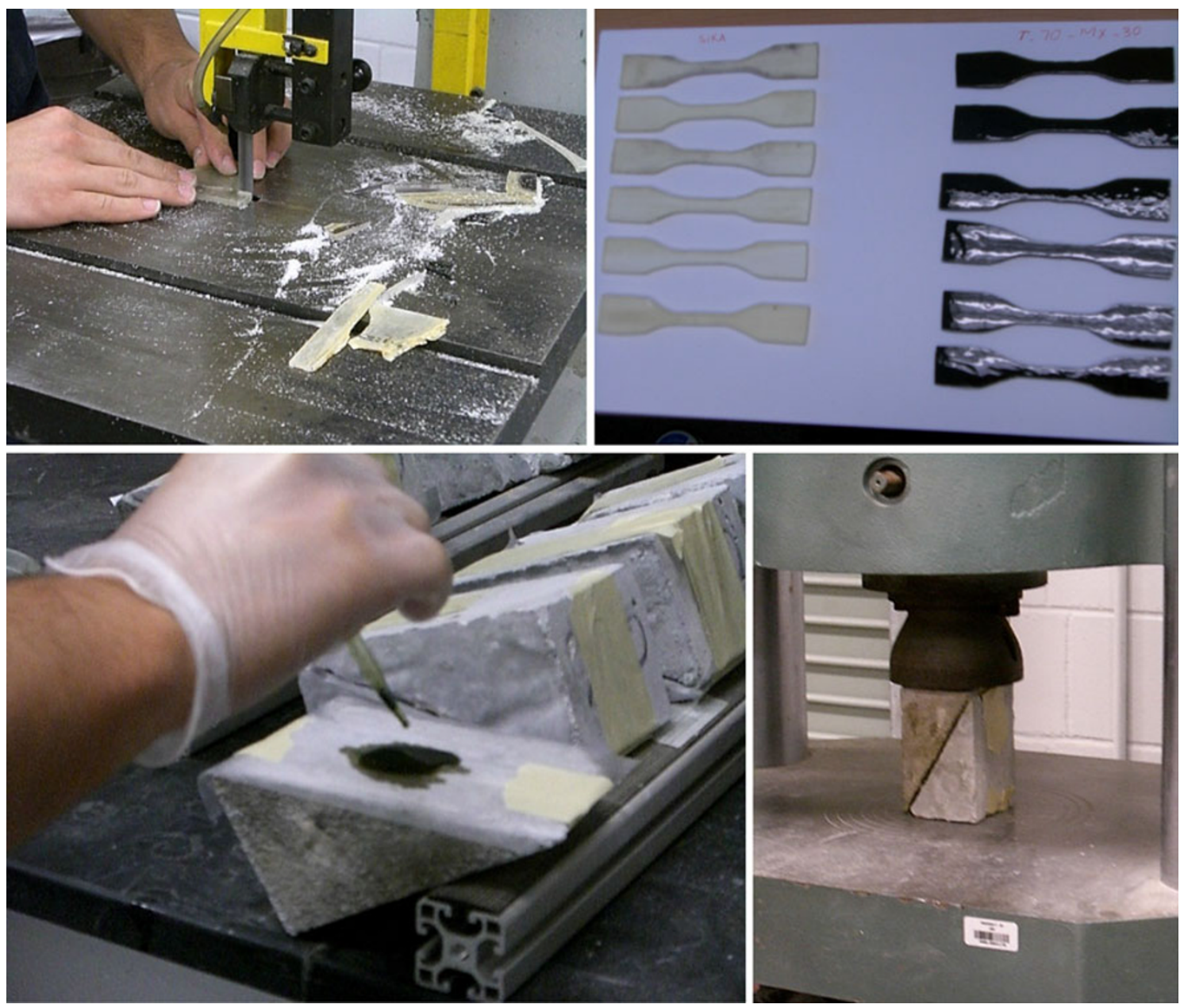

Fig. 6 Specimen preparations and testing.

Table 3 Results of testing the sealant materials in the laboratory.

\begin{tabular}{|c|c|c|c|c|c|c|c|}
\hline \multicolumn{4}{|c|}{ Manufacturer's data } & \multicolumn{2}{|c|}{ Lab test data (first attempt) } & \multicolumn{2}{|c|}{ Lab test data (second attempt) } \\
\hline \multirow[t]{2}{*}{ Product } & Tensile strength & \multirow[t]{2}{*}{ Viscosity (cps) } & \multirow[t]{2}{*}{ Elongation (\%) } & Tensile strength & \multirow[t]{2}{*}{ Elongation (\%) } & Tensile strength & \multirow[t]{2}{*}{ Elongation (\%) } \\
\hline & $\mathrm{MPa}$ & & & $\mathrm{MPa}$ & & $\mathrm{MPa}$ & \\
\hline $1-\mathrm{A}$ & 56.4 & $5-15$ & 5.5 & 22.6 & 2.1 & 25.3 & 2.6 \\
\hline $2-\mathrm{B}$ & $41.0-47.9$ & 30 & $3-7$ & 23.4 & 10.5 & 27.2 & N/A \\
\hline $3-\mathrm{C}$ & 19.3 & $5-20$ & $40-50$ & 0.9 & 99.6 & 7.3 & 17.2 \\
\hline $4-\mathrm{D}$ & 8.2 & $10-25$ & 30 & No test & No test & 5.7 & 1.3 \\
\hline $5-\mathrm{E}$ & 6.9 & 80 & 60 & 3.3 & 213 & 5.4 & 102 \\
\hline
\end{tabular}

sealant materials appear to have an acceptable penetration. The penetration test was performed on some of the core samples using the water drop test procedure.

\section{Laboratory Investigation}

Following the field investigation, a comprehensive testing was done in the laboratory. Laboratory tests were performed on samples of prepared sealing materials, bonded concrete specimens, and slab samples. Tests were performed on the sealing materials according to the ASTM specifications. Figure 6 shows the preparation of samples and testing. The five sealant materials mentioned earlier were selected from a list of sealers and also were those closely matched the qualified products list (QPL) of the Florida Department of Transportation. Table 3 shows the results of testing the sealant materials in the laboratory.

Down-scaled six slab specimens were constructed to further examine the sealant materials. The concrete used the recommended Type II Portland Cement with a designed compressive strength (f'c) of $34.5 \mathrm{MPa}$ and an actual compressive strength of 54.9 MPa. The slabs are $45.7 \mathrm{~cm}$ wide, $1.22 \mathrm{~m} \mathrm{long}$, and $14.0 \mathrm{~cm}$ thick. The Lab testing was conducted, on slab models constructed having a blade placement to create "ideal" cracks of $0.25(\mathrm{CH}-0)$ to $0.50(\mathrm{CH}-1) \mathrm{mm}$ in width and a spacing of 
(a)

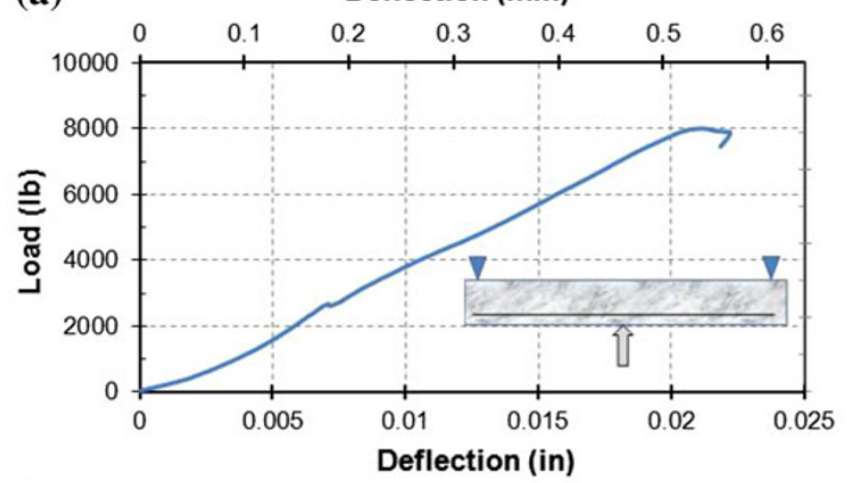

(c)

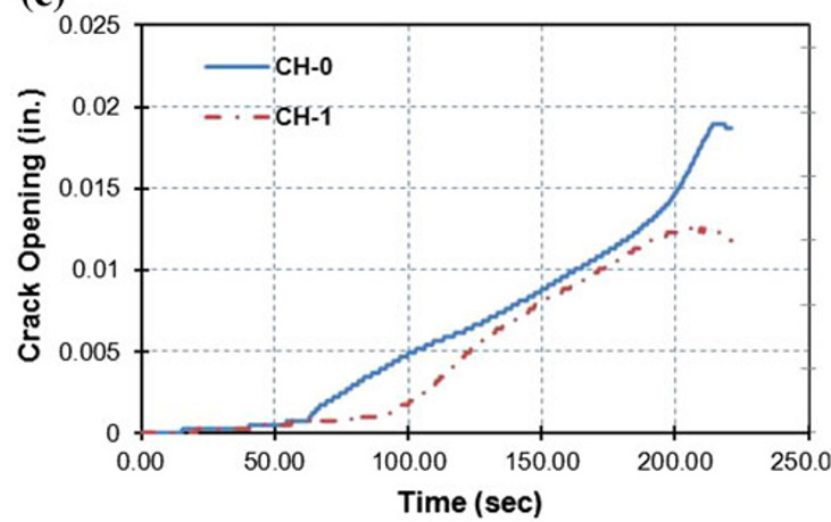

Fig. 7 Results of Slab 1-A due to application of single load and double load. a Load-deflection relationship due to application of single load. b Load-deflection

$10.2 \mathrm{~cm}$ on center. Since it was determined, from the field investigation, that the crack width is not constant, a set of plates were created with two different widths and lengths to plunge into the concrete, while still in the plastic stage, and be removed before the final set of concrete. The process resulted in two different crack widths $(0.25-0.50 \mathrm{~mm})$ and two different crack lengths $(22.9-45.7 \mathrm{~cm})$ providing the opportunity to test specimens with various crack widths and lengths. The slab specimens were tested under single and double loads. When the load was applied; load, time, deflection, and crack opening were monitored for all of the specimens. It is important to note that crack opening was monitored for cracks that run through the entire slab width only. Shorter crack was monitored for only propagation of crack. The control slab, without any induced cracks, was tested to a force of $32 \mathrm{kN}$ at which three cracks equally spaced at $\sim 10.2 \mathrm{~cm}$ were developed. The remaining five (5) slab specimens were sealed with the assigned sealer, as per Table 3, allowed to cure, then were subjected to the single point load to examine the behavior of the sealer under load. A sample of results of the load testing of the slabs are also shown in Fig. 7. When slab 1-A was tested under a single line load, center crack sealer started to debond at $28.9 \mathrm{kN}$ while other cracks did not appear to react to the applied load. Therefore, a second test with two line loads was performed to produce moment, close to the outside cracks. Under the application of the double load, the outside crack propagated without showing any evidence of sealant debonding. The test results of slab 1-A due to application of double line load are shown also in Fig. 7. (b)

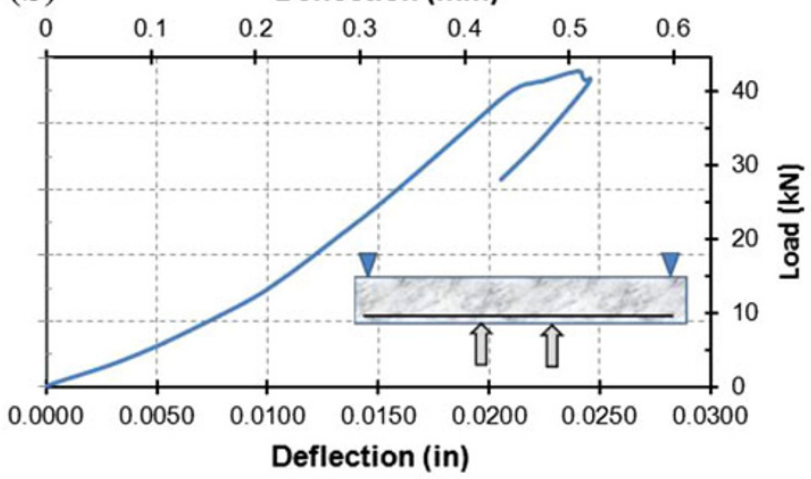

(d)

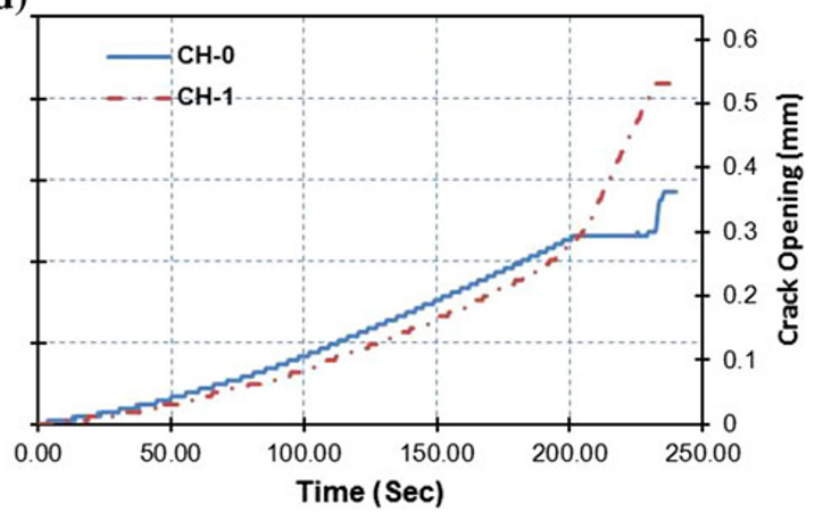

relationship due to application of double load. $\mathbf{c}$ Crack opening due to application of single load. d Crack opening due to application of double load.

It can be observed that specimen sustained more load under the application of double load than that under the application of single load. As mentioned earlier, under single load, the center crack opened more than off-center crack, however, under double load, the off-center crack opened more. Ultimately, the total crack width, the sum of initial crack width and crack opening, of $\mathrm{CH}-0$ and $\mathrm{CH}-1$ due to double load were almost the same. Figure 8 shows load-deflection curves of remaining slab specimens due to application of single and double loads. It can be noted that less debonding was observed for specimens sealed with sealant materials that have larger tensile elongation percent. It seems that the use of this type of materials allows the crack to open up without failure of connection between the crack walls thus the sealant materials showed superior characteristics. The results of the testing showed that the 3-part HMWM sealer is most suitable for cracks with width between 0.25 and $0.50 \mathrm{~mm}$, whereas the epoxy sealer is most suitable for cracks with wider widths than $0.50 \mathrm{~mm}$.

\section{Analytical Investigation}

This part of the study included performing finite element modeling, conducting analyses, and discussion of Florida department of transportation (FDOT) Steel Girder Bridges in order to limit the development of transverse bridge deck cracking. Many parameters may affect the performance of steel girder bridge such as; load patterns, load magnitudes, 
(a)

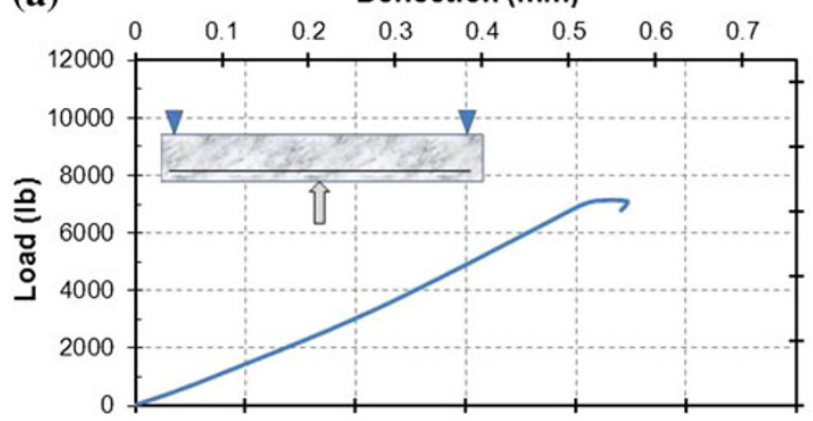

(c)

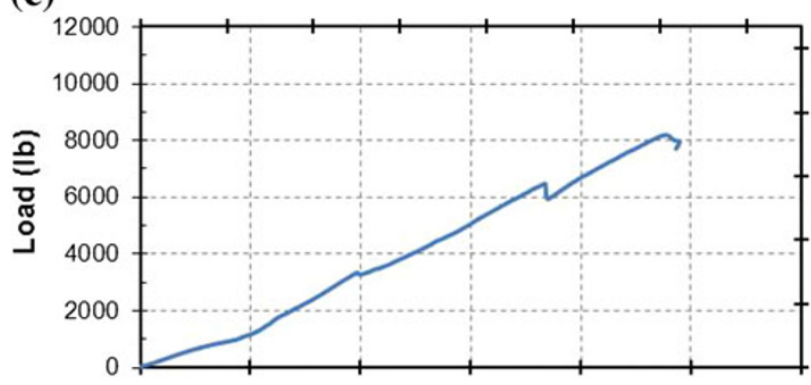

(e)

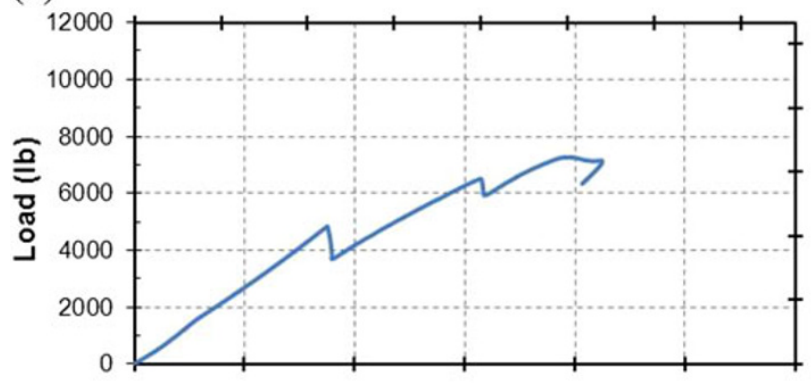

(g)

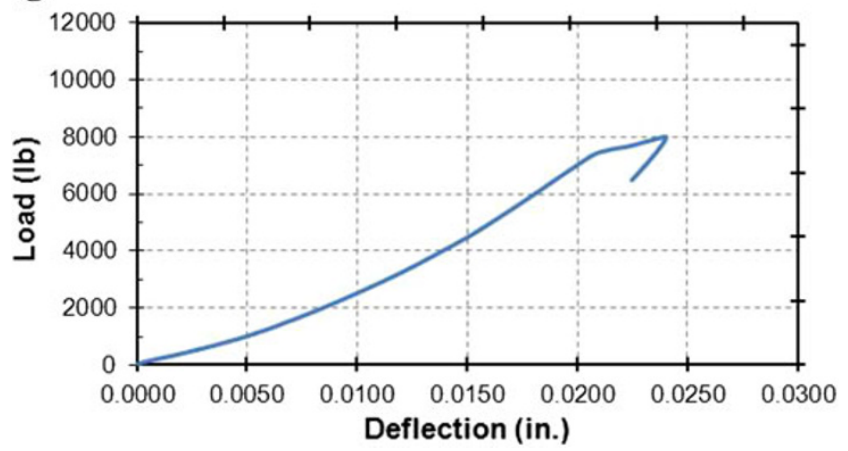

Fig. 8 Load-deflection relationship of a Slab 2-B due to single load. b Slab 2-b due to double load. c Slab 3-C due to single load. d Slab 3-C due to double load. e Slab 4-D

deflection limits, bridge span length, bridge continuity, structural system, and others. This analytical study examines the effect of several parameters on the development of transverse cracking in bridge decks including the effect of creep, shrinkage, thermal expansion, strength of concrete, deck thickness, bridge span length, bridge continuity, traffic load and load patterns, and boundary conditions. A benchmark bridge (Fig. 9) was selected. The bridge has reinforced concrete (RC) deck, which is $21.6 \mathrm{~cm}$ thick, and supported by four steel plate girders. The spacing between girders is (b)

Deflection ( $\mathrm{mm}$ )

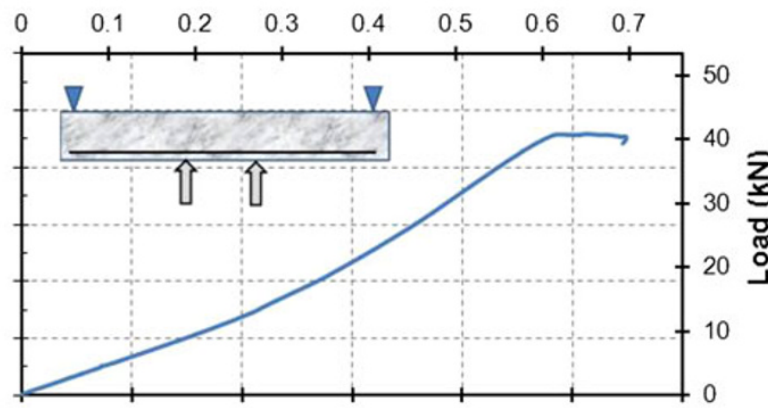

(d)

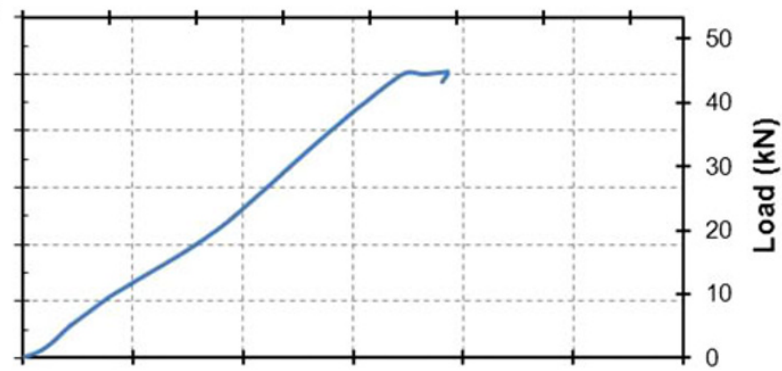

(f)

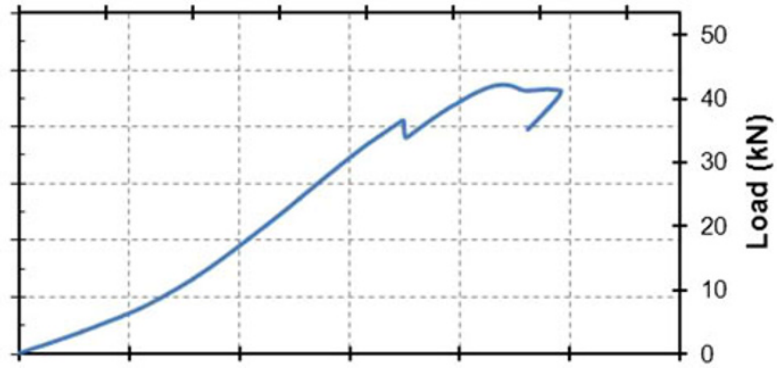

(h)

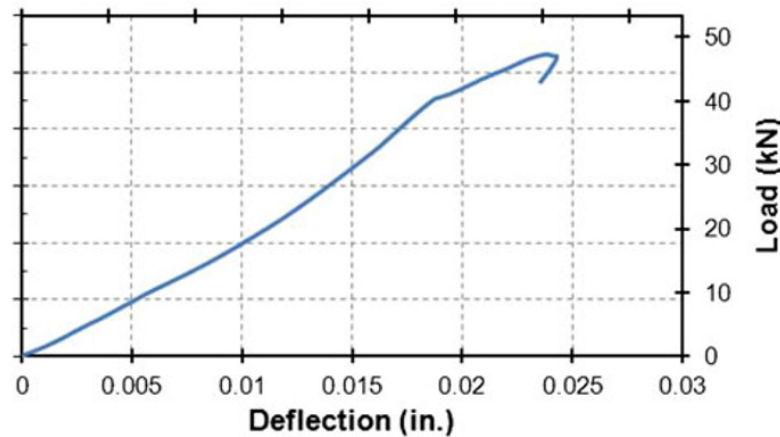

due to single load. f Slab 4-D due to double load. g Slab 5 -E due to single load. $\mathbf{h}$ Slab 5-E due to double load.

$3.43 \mathrm{~m}$. The span of the bridge is $56.1 \mathrm{~m}$. The selected bridge was altered to cover different parameters of interest (number of spans, span length, deck aspect ratio, etc.).

\subsection{Modeling}

A 3-D finite element model of the bridge was completed. The model includes a 3-D finite element model of RC deck and steel I-girders. The steel plate girders of A992 steel were modeled using shell elements (Fig. 10). The shell elements are four-node quadrilateral elements. The shell elements 


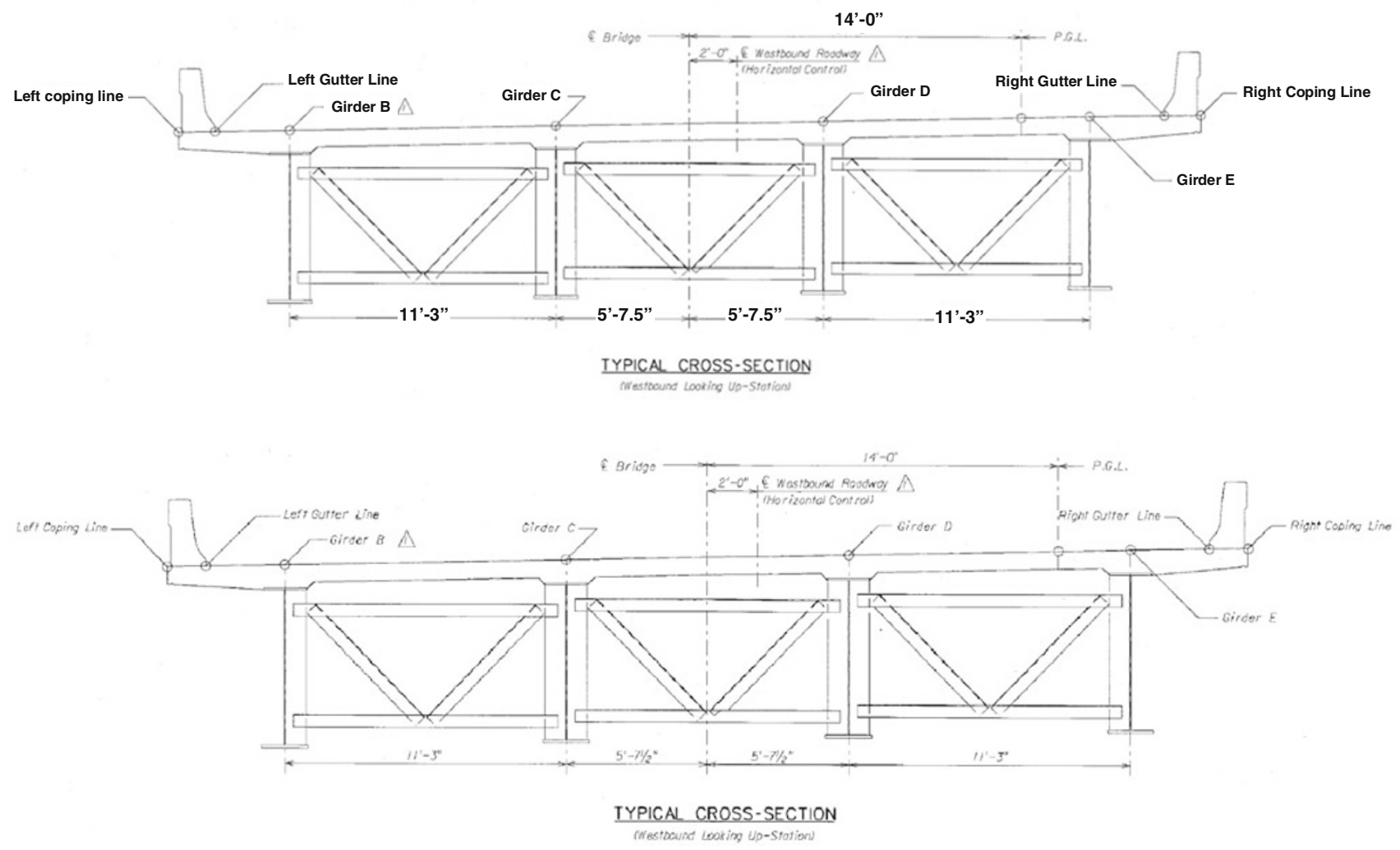

Fig. 9 Benchmark bridge cross section (Conversion: $1 \mathrm{ft} .=305 \mathrm{~mm} ; 1$ in. $=25.4 \mathrm{~mm}$ ).

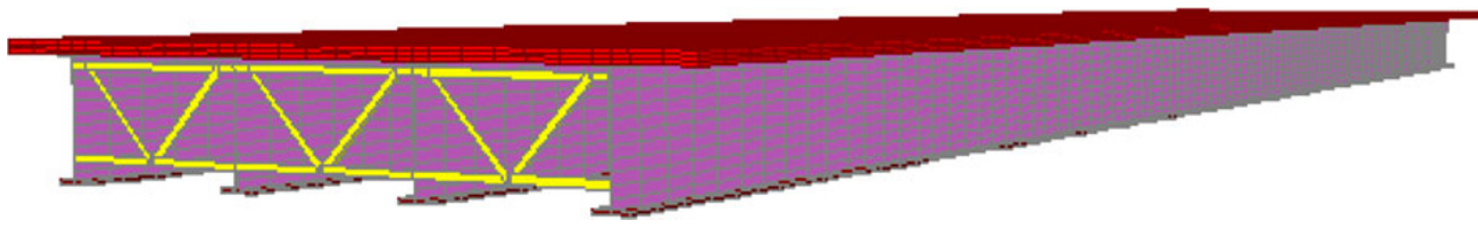

Fig. 10 Typical 3-D bridge model.

were used to model top and bottom flanges and the web as well. Each flange was modeled using large number of shell elements; elements were in the longitudinal direction and in the transverse direction. Each web was modeled using shell elements ensuring compatibility with elements used to model the flanges. Since the objective of the study is to investigate the tendency of bridge decks to develop transverse cracks, the RC bridge deck was modeled more accurately using 8 -node solid element. It is important to note that the same distribution and number of elements used to model girder flanges were used to model the parts of deck above flanges to ensure joint connectivity and compatibility.

To include all of the parameters, the properties of benchmark bridge were altered to produce models, which are general enough to cover all of the listed parameters. Table 4 shows the main characteristics of bridge models developed to address the parameters.

Several load patterns are included in the study. Load patterns include dead load, increase in temperature due to hydration, temperature, shrinkage, creep, and truck loads. Only bridge deck was subjected to increase in temperature due to hydrations, which is assumed to be $20^{\circ} \mathrm{C}$. The temperature load was taken as a uniform increase in temperature of bridge deck and girders by $29.4{ }^{\circ} \mathrm{C}$. The effect of shrinkage was considered through applying a strain due to shrinkage on bridge decks.

\section{Results and Discussion}

\subsection{Truck Load}

Unshored construction is a common practice in bridge construction, particularly, for steel I-girder bridges. Therefore, the dead load effect was not considered. In order to produce the maximum moment and in turn a higher potential of cracking, the first and third span of the bridge was loaded with truck load (TR) while the middle span was free of TR (Fig. 11). This designed scenario was selected to ensure that the case, at which maximum tensile stress to develop in the deck, is considered. It is important to note that different types of loads were applied to the 3-span bridge model. The applied loads were not only live load but also shrinkage (SH), drop in temperature (TE) of $29.4{ }^{\circ} \mathrm{C}$ were applied. The temperature load was only applied to the bridge deck while the temperature of steel I-girders was assumed to remain unchanged. It was found that increasing or decreasing the temperature affects the tendency of the bridge 


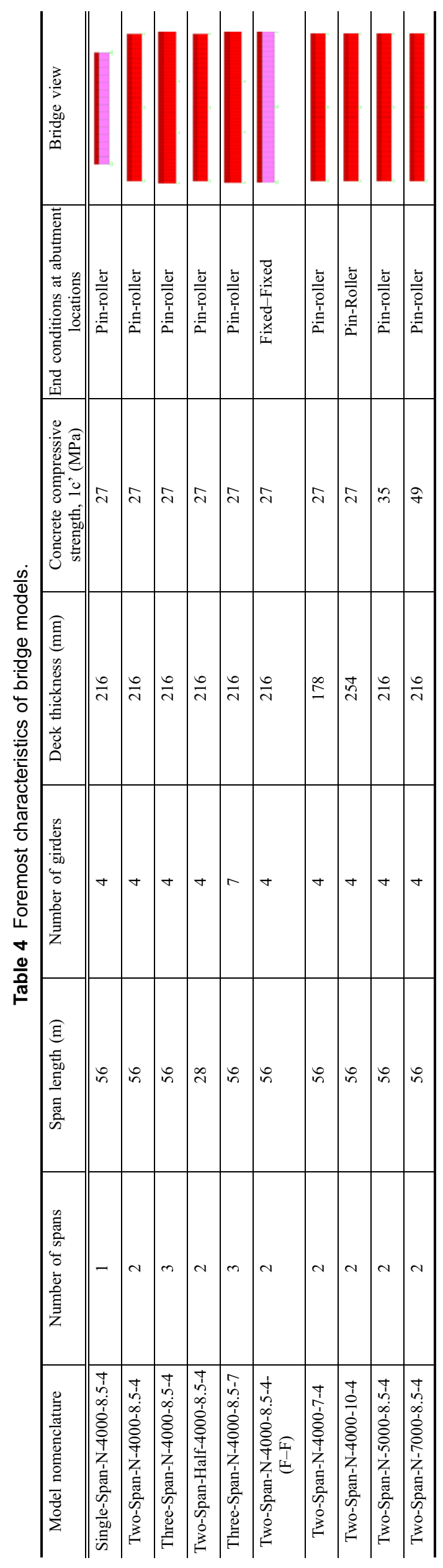

deck to develop transverse cracking in different manner therefore the effect of both increasing and decreasing the temperature was considered in the study. Table 5 presents the results of this part of the study.

Deck cracking may be initiated by shrinkage therefore these cracks become working cracks. When the live load is applied, these cracks may open up further. Therefore, it is important to simulate the described case. Since the increase in live load will increase elongation of cracks and crack width, the live load due to TR was incrementally increased. The live load cases include application of 50, 75,100 , and $125 \%$ of HS-20 TR (Table 6). The increase of the live load tends to further open the crack up and hence the crack width increases. Furthermore, a combined effect of loads was studied. The combined case of TR with either shrinkage or decrease of temperature was considered since shrinkage and decrease of temperature cases were proven to drive the development of transverse deck cracking. Figures 12 to 15 show a sample of stress contours and deflected shape of the bridge deck due to the applications of different loads.

\subsection{Effect of Secondary Loads}

The secondary loads include hydration, temperature, shrinkage, and creep. As mentioned, hydration effect was considered by applying $20{ }^{\circ} \mathrm{C}$ of temperature load to all of decks of bridge models. Temperature effect was considered by applying an increase of temperature of $29.4{ }^{\circ} \mathrm{C}$ to bridge deck and girders. Shrinkage effect was considered by applying the proper value of strain due to shrinkage for the deck of each bridge model. Creep was accounted for also by applying the proper value of strain to bridge deck.

\subsubsection{Hydration}

By applying the hydration effect to the decks of bridge models, it was determined that the maximum tensile stress to produce transverse cracking takes place at the top of the bridge decks and at the girders locations. From Fig. 16, tensile stress due hydration does not seem to have potential thread to produce transverse cracking for the pin-roller boundary conditions. Also, it was observed that the tensile stresses developed in bridge decks increased with the age of the concrete and with the increase of number of spans.

\subsubsection{Temperature}

By applying the temperature effect to all of the bridge models, it was determined that the maximum tensile stress to produce transverse cracking takes place at the bottom of the bridge decks and at the location of girders. From Figs. 17 and 18, tensile stresses developed due to increase in temperature are small and do not resemble a potential cause for transverse deck cracking if seat-type abutments is used. However, when the fixity was introduced (Fig. 19), tensile stresses increased significantly and transverse cracking took place. It was observed that stresses slightly increased with the number of spans. Therefore, continuity in bridges can lead to larger likelihood of transverse cracking development. It seems that increase in span length does not affect the stresses developed due to temperature effect. 
$1^{\text {st }} \operatorname{span} \quad$ mid span $\quad 3^{\text {rd }} \operatorname{span}$

LL

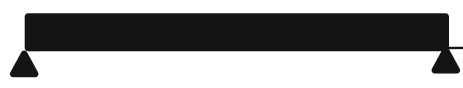

$56 \mathrm{~m}$
0 gravity load

$56 \mathrm{~m}$
LL

$56 \mathrm{~m}$

Fig. 11 Load scenario.

Table 5 Summary of results.

\begin{tabular}{c|c|c|c}
\hline Loading case & Moment $(\mathrm{kN}-\mathrm{cm})$ & Deflection $(\mathrm{mm})$ & Remarks \\
\hline \hline Shrinkage (SH) & 164.2 & $18.3 \uparrow$ & Cracked \\
\hline Temp. $\left(\right.$ TE-increase) $^{\mathrm{a}}$ & 10.8 & $18.5 \downarrow$ & No cracks \\
\hline Temp. $\left(\right.$ TE-decrease) $^{\mathrm{a}}$ & 130.6 & $15.2 \uparrow$ & Cracked \\
\hline Truck (TR) & No cracks \\
\hline SH + TR & 15.6 & $22.9 \uparrow \uparrow$ & Cracked \\
\hline (TE-increase) + TR $_{(\text {TE-decrease) }+ \text { TR }}^{179.6}$ & 10.3 & $15.5 \downarrow$ & No cracks \\
\hline SHR + TR + (TE-increase) & 145.9 & $24.1 \uparrow$ & Cracked \\
\hline SHR + TR $+($ TE-decrease) & 51.8 & $7.6 \uparrow$ & Cracked \\
\hline
\end{tabular}

${ }^{\text {a }}$ Values presented are due to $29.4{ }^{\circ} \mathrm{C}$ of an increase or decrease of temperature. Decreasing temperature may lead to transverse cracking.

b 2.1 HS-20 will cause transverse deck cracking.

Table 6 Summary of results-incrementally increase of truck load and a decrease of temperature of $29.4{ }^{\circ} \mathrm{C}$.

\begin{tabular}{c|c|c|c|c}
\hline Loading case & Stress $(\mathrm{MPa})$ & Moment $(\mathrm{kN}-\mathrm{cm})$ & Deflection $(\mathrm{mm})$ & Remarks \\
\hline \hline TE + 0.5TR & 13.6 & 138.3 & $22.1 \uparrow$ & \\
\hline $\mathrm{TE}+0.75 \mathrm{TR}$ & 14.0 & 142.1 & $23.1 \uparrow$ & \\
\hline $\mathrm{TE}+\mathrm{TR}$ & 14.3 & 145.9 & $24.1 \uparrow$ & \\
\hline $\mathrm{TE}+1.25 \mathrm{TR}$ & 14.7 & 149.8 & $25.4 \uparrow$ & \\
\hline
\end{tabular}

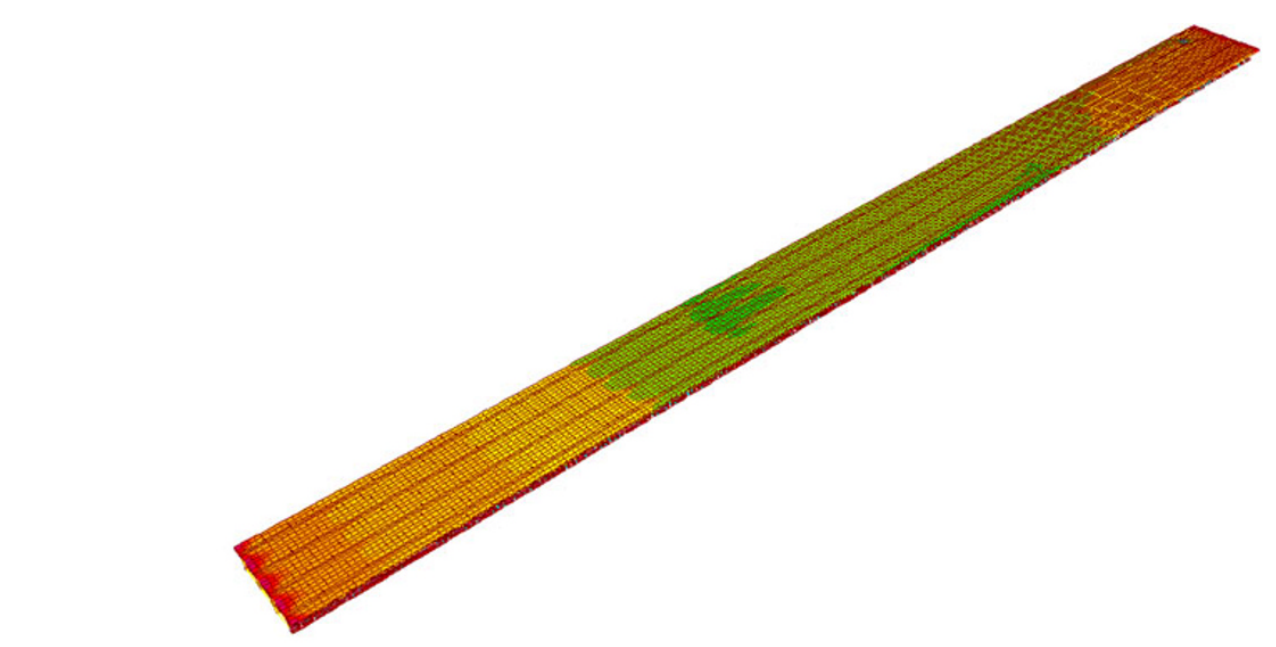

Fig. 12 Stress contours due to shrinkage.

90 | International Journal of Concrete Structures and Materials (Vol.7, No.1, March 2013) 
Fig. 13 Bridge deformed shape due to shrinkage.

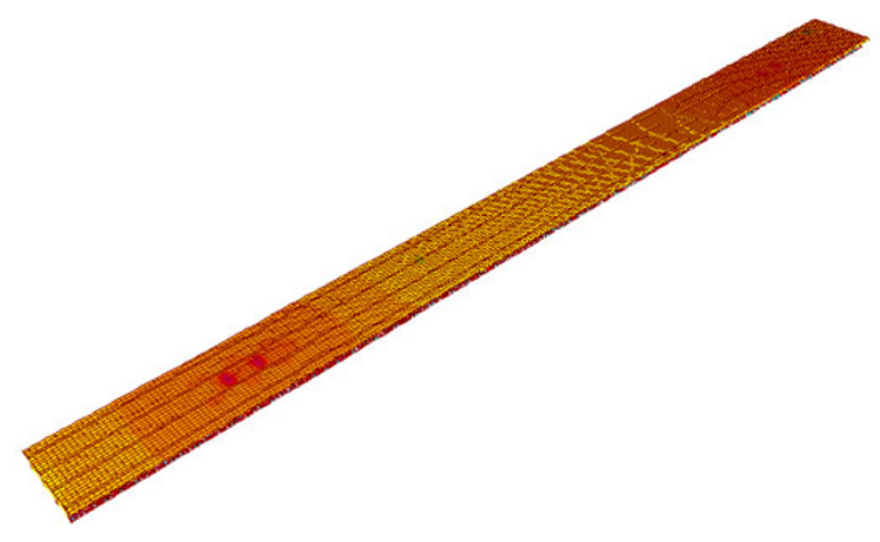

Fig. 14 Stress contours due to truck load.

Fig. 15 Bridge deformed shape due to truck load.

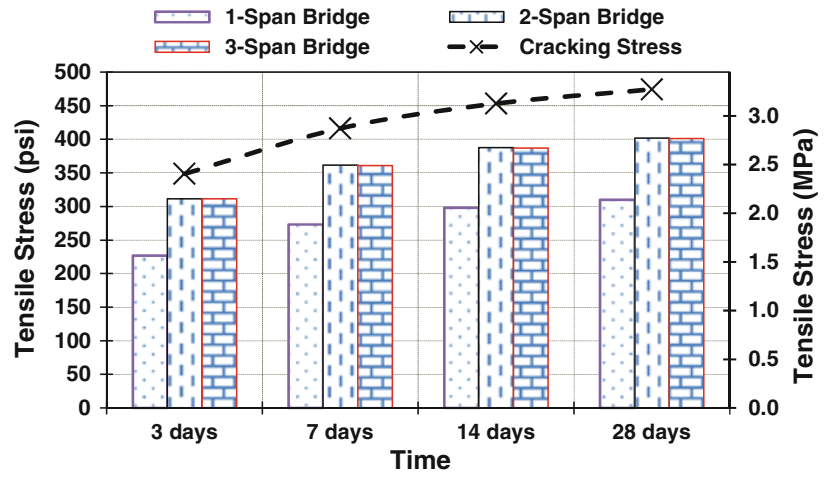

Fig. 16 Effect of hydration (number of spans).

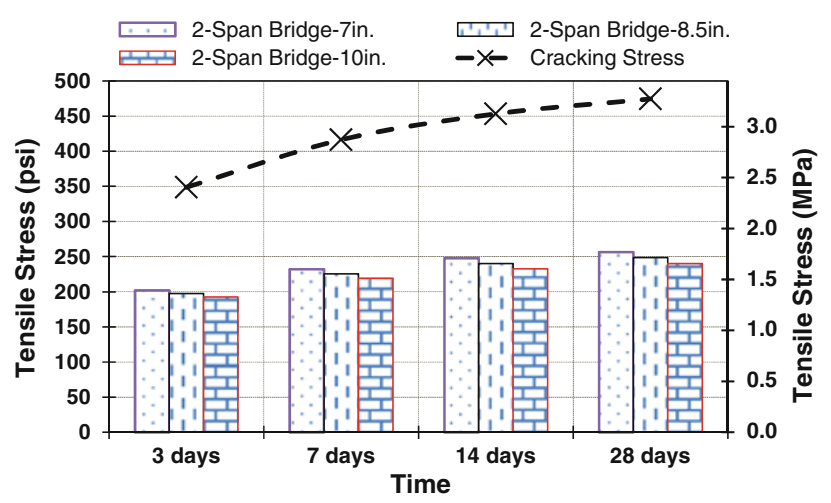

Fig. 17 Effect of temperature (deck thickness).

The same conclusion can be drawn for the effect of spacing between girders. It seems that the stiffer (thicker) the concrete deck, the lower the tensile stresses is (Fig. 17). However, the effect of deck thickness is marginally pronounced. It was also found that the higher the concrete compressive strength, the

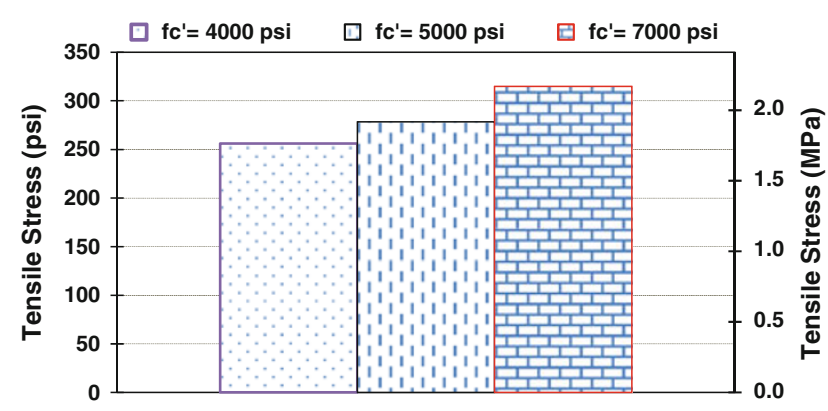

Fig. 18 Effect of temperature $\left(f_{c}\right)$.

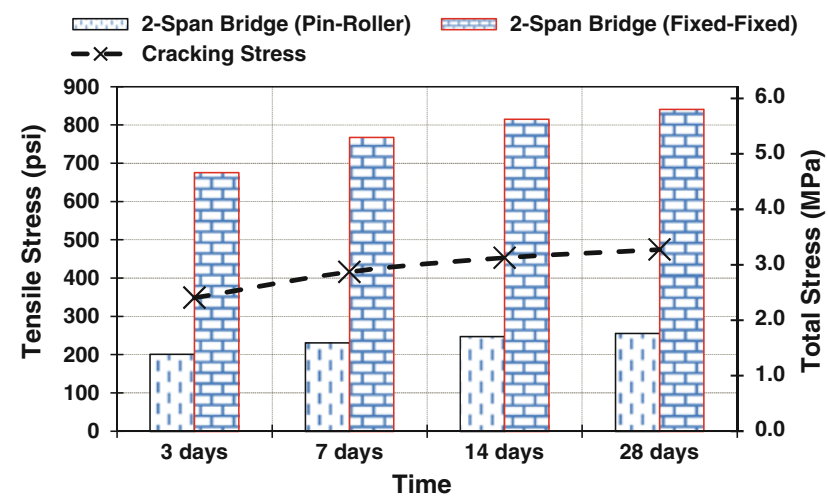

Fig. 19 Effect of temperature (boundary conditions).

higher the tensile stresses developed (Fig. 18) which could lead to transverse deck cracking. It is recommended to use an average concrete compressive strength and to avoid the use of concrete with very high compressive strength, to limit development of such transverse cracks. 


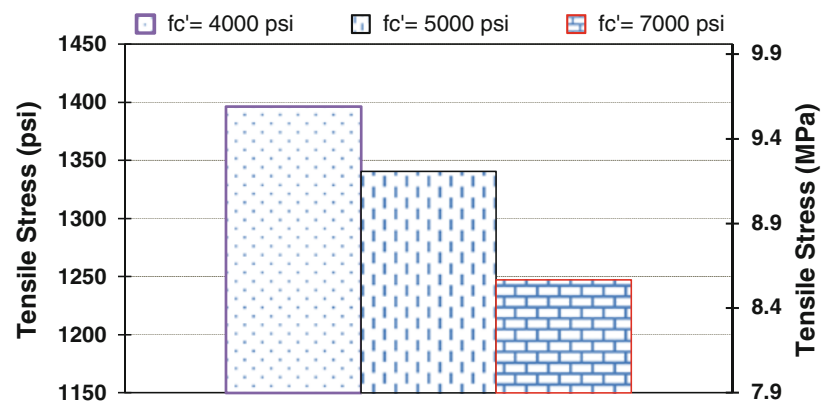

Fig. 20 Effect of shrinkage $\left(f_{c}\right)$.

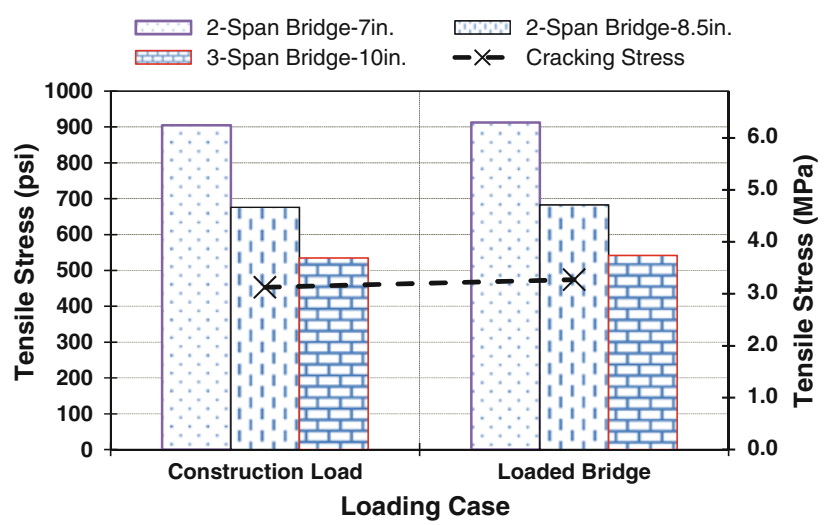

Fig. 21 Longitudinal tensile stresses due to truck loads (Deck thickness).

\subsubsection{Shrinkage}

As mentioned earlier, shrinkage was applied as a strain to the decks of bridge models. Tensile stresses developed due to shrinkage (Fig. 20) were found larger than those developed due to hydration and temperature. It is determined that transverse cracking starts to produce at 7 days. The transverse cracks initiate near the steel girders and deck overhang. It was observed that continuity increased slightly the stress, however, all of bridges developed transverse cracks due to shrinkage at 7, 14, and 28 days. There were not any cracks developed at 3 days. In addition, the increase of the deck thickness reduces the developed stress, which may lead to fewer cracks throughout (Fig. 21). When the concrete compressive strength increases the developed stress becomes smaller. This trend is opposite to what presented before. Increasing the girder spacing and span length did not seem to have a significant effect on the likelihood of transverse deck cracking. In light of presented observations, it is recommended to avoid fixed boundary conditions and use a thicker bridge decks as well as a moderate concrete compressive strength to limit transverse cracking of bridge decks.

\section{Conclusions}

The goal of this study is to provide a better understanding of the issue of transverse deck cracking. This study examined the use of a wide range of sealant materials in the lab and in the field. The study also presented an analytical study in an effort to enhance the current knowledge of the issue of transverse deck cracking. In light of this study, the following conclusions can be drawn:
- All of the tested sealers performed well. The sealed slabs performed very close to the control slab.

- The three-part HMWM performed best for cracks $<0.50 \mathrm{~mm}$ in width and the Epoxy was the best performer for cracks $\geq 0.50 \mathrm{~mm}$ in width.

- The concrete compressive strength has an important contribution. Different conclusions can be drawn depending on the type of the applied load. It is recommended to use a moderate compressive strength concrete for bridge decks. It is recommended the use of a compressive strength of no more than $34.5 \mathrm{MPa}$ as transverse cracking develops exponentially at higher compressive strengths.

- Shrinkage or temperature tends to drive the initiation of cracking and hence cracks developed become working cracks. Application of live loads widens the induced cracks even further.

- The stiffness of the bridge deck is also an important parameter and affects the behavior. The thicker the deck, the lower the stress developed, resulting in fewer cracks. Based on this study, it is recommended to use a deck thickness of more than $17.5 \mathrm{~cm}$.

- The deflection limit given by AASHTO affects the likelihood of cracking and should be revised to account for higher values of crack widths found in this research.

- More research is needed in the area of crack behavior during the loading phase and the reaction of the sealer to crack opening and closing.

\section{Open Access}

Open Access This article is distributed under the terms of the Creative Commons Attribution License which permits any use, distribution, and reproduction in any medium, provided the original author(s) and the source are credited.

\section{References}

ACI Committee 224. (2001). Control of cracking in concrete structures (ACI 224R-01). Farmington Hills, MI: American Concrete Institute.

Altoubat, S. A., \& Lange, D. A. (2000). Creep, shrinkage and cracking of restrained concrete at early age. Urbana, IL: University of Illinois at Urbana-Champaign.

Cady, P. D., Carrier, R. E., Bakr, T. A., \& Theisen, J. C. (1971). Final report on the durability of bridge deck concrete. Harrisburg, PA: Pennsylvania Department of Transportation.

Eppers, L. J., French, C. E., \& Hajjar, J. (1998). Transverse cracking in bridge decks. Summary Report 1999-2005. St. Paul, MN: Minnesota Department of Transportation.

Frosch, R. J., Blackman, D. T. \& Radabaugh, R. D. (2003). Investigation of bridge deck cracking in various bridge superstructure systems. Publication FHWA/IN/JTRP-2002/25. Joint Transportation Research Program. West Lafayette, IN: Indiana 
Department of Transportation and Purdue University. doi: 10.5703/1288284313257.

Krauss, P. D., \& Rogalla, E. A. (1996). Transverse cracking in newly constructed bridge decks. National Cooperative Highway Research Program (NCHRP) Report 380, Transportation Research Board.

Portland Cement Association. (1970). Final report-durability of concrete bridge decks. Skokie, IL: Portland Cement Association.

Purvis, R., Babei, K., Udani, N., Qanbari, A., \& Williams, W. (1995). Premature cracking of concrete bridge decks. Causes and methods of prevention. In Proceedings of the 4th International Bridge Engineering Conference, Washington, DC.

Rodler, D. J., Whitney, D. P., Fowler, D. W., \& Wheat, D. L. (1989). Repair of cracked concrete with high molecular weight methacrylate monomers. Polymers in Concrete Advantages and Applications. Farmington Hills, MI: American Concrete Institute, SP-116.

Saadeghvaziri, M., \& Hadidi, R. (2002). Cause and control of transverse cracking in concrete bridge decks. Final Report
FHWA-NJ-2002-019. Trenton, NJ: Department of Transportation.

Schmitt, T. R \& Darwin, D. (1995). Cracking in concrete bridge decks. Final Report K-TRAN: KU-94-1, Lawrence, KS.

Soriano, A. (2002). Alternative sealants for bridge decks: Final report. Pierre, SD: South Dakota Department of Transportation Office of Research.

Sprinkel, M. M. (1998). Very-early strength latex-modified concrete overlay. Technical Report VTRC99-TAR3. Charlottesville, VA: Virginia Transportation Research Council.

Tsiatas, G., \& Robinson, J. (2002). Durability evaluation of concrete crack repair systems. Transportation Research Record, 1795, 82-87.

Xi, Y., Shing, B., Abu-Hejleh, N., Asiz, A., Suwito, A., Xie, Z., \& Ababneh, A. (2003) Assessment of the cracking problem in newly constructed bridge decks in Colorado. Final Report CDOT-DTD-R-2003-3. Denver, CO: Colorado Department of Transportation. 